\title{
Observatório
}

ISSN n² 2447-4266

Vol. 4, n. 3, maio. 2018

DOI: https://doi.org/10.20873/uft.2447-4266.2018v4n3p783

\section{ESVAZIAMENTO DO \\ SUJEITO PELO \\ DISCURSO: mídia e a \\ prática do \\ esquecimento}

\author{
DEPRIVING THE MAN BY \\ DISCOURSE: media and the \\ practice of forgetting
}

VACIAMIENTO DEL SUJETO POR EL

DISCURSO: medios y la práctica del

olvido

\section{Zilda Martins Barbosa ${ }^{1,2}$}

\section{RESUMO}

Esse trabalho pretende compreender como a mídia esvazia de sentido determinado segmento da sociedade, a exemplo do afrodescendente, historicamente subalternizado e esquecido já no próprio ato da abolição, que foi feita em dois parágrafos. Livre, o ex-escravizado não adquiriu cidadania de fato, saindo da condição de mercadoria para o nada de condição. Parafraseando Rancière, o homem foi substituído pelo discurso sobre o homem, este sendo esvaziado midiaticamente em sua subjetividade. Pretendo trabalhar com o conceito de memória, de Pollack e Pierre Nora. A base teórica desse trabalho também se apoia em Jacques Rancière em Frantz Fanon e Muniz Sodré.

PALAVRAS-CHAVE: Afrodescendente; discurso de mídia; invisibilização; memória; ações afirmativas.

\footnotetext{
${ }^{1}$ Doutora em Comunicação e Cultura (UFRJ). Mestrado em Comunicação (UFRJ). Graduação em Comunicação Social (Faculdade de Comunicação e Turismo Hélio Afonso - RJ). Email: zildamarti@yahoo.com.br.

${ }^{2}$ Endereço de contato com os autores (por correio): Universidade Federal do Rio de Janeiro (UFRJ) - Coordenadoria de Comunicação Social - Avenida Horácio Macedo - Cidade Universitária - Rio de Janeiro - RJ, Brasil.
} 
ISSN n² 2447-4266

Vol. 4, n. 3, maio. 2018

DOI: https://doi.org/10.20873/uft.2447-4266.2018v4n3p783

\begin{abstract}
This paper intends to understand how the media deprives certain segment of society, as the Afrodescendant, historically subalternized and forgotten during the act of Abolition, which was made in two paragraphs. Freed, the former enslaved did not in fact acquire citizenship, leaving the condition of being a commodity to turn nothing at all. To paraphrase Rancière, man was replaced by the discourse of man, who was emptied in his subjectivity. I intend to work on this concept of collective memory by Halbwachs and Nora. The theoretical basis of this work is also based on Jacques Rancière in Frantz Fanon and Muniz Sodré.
\end{abstract}

KEYWORDS: Afrodescendant; media speech; invisibilization; memory; affirmative action.

\title{
RESUMEN
}

Este trabajo pretende compreender cómo los medios vacíos de sentido determinado segmento de la sociedad, a ejemplo del afrodescendiente, históricamente subalternizado y olvidado ya en el acto mismo de la abolición, que se hizo en dos párrafos. Libre, el ex-esclavizado no adquirió ciudadanía de hecho, saliendo de la condición de mercancía para la nada de condición. Parafraseando a Rancière, el hombre fue sustituido por el discurso sobre el hombre, este siendo vaciado mediáticamente en su subjetividad. La propuesta es trabajar con el concepto de memoria, de Pollack y Pierre Nora. La base teórica de este trabajo también se apoya en Jacques Rancière em Frantz Fanon y Muniz Sodré.

PALABRAS CLAVE: Afrodescendiente; discurso de los medios de comunicación; invisibilización; memoria; acciones afirmativas.

Recebido em: 11.11.2018. Aceito em: 16.03.2018. Publicado em: 29.04.2018. 


\section{Observotório}

ISSN n² 2447-4266

Vol. 4, n. 3, maio. 2018

DOI: https://doi.org/10.20873/uft.2447-4266.2018v4n3p783

Se você não cuidar, os jornais farão você odiar as pessoas que estão sendo oprimidas, e amar as pessoas que estão oprimindo.

MALCOLM X

\section{Introdução}

A origem dicionarizada da palavra comunicação vem do latim, communicatio, que significa "tornar comum". Derivado de communis + actio, adquire o sentido de "ação do comum", "ato de repartir", "dividir", "distribuir", ou seja, comunicação quer dizer "o ato de compartilhar o comum entre muitos." De acordo com Muniz Sodré, pensando numa ciência da comunicação, é importante "associar à questão moderna a velha noção de communicatio [...] para designar a coesão social sob o ângulo de uma transcendência, que é a do 'diálogo entre os deuses e os homens." (SODRÉ, 2014, p. 191). Tal diálogo, ressalta o autor, não seria um mero intercâmbio de palavras, mas "uma ação de fazer ponte entre as diferenças, que concretiza a abertura da existência em todas as suas dimensões e constitui ecologicamente o homem no seu espaço de habitação - portanto, como categoria ética." (SODRÉ, 2014, p. 191).

A questão que se coloca é saber se a comunicação no Brasil cumpre o seu papel da ação de compartilhar o comum entre todos ou se, ao contrário, escolhe lembrar de uns e esquecer de outros? Levando à linguagem contemporânea da comunicação ampliada, qual o compromisso ético da mídia com relação ao afro-brasileiro? Muniz Sodré considera que tem pouca valia o olhar voltado para a técnica, considerando que "enxergar apenas o sistema e a máquina é cegar-se para o que, no homem, é potencialmente abertura." (Idem). É dessa comunicação humana, do sujeito como abertura para si mesmo e, 


\section{Observatório}

ISSN n² 2447-4266

Vol. 4, n. 3, maio. 2018

DOI: https://doi.org/10.20873/uft.2447-4266.2018v4n3p783

consequentemente, para viver a experiência do diverso, que esse trabalho pretende chamar a atenção, considerando a igualdade de direitos, para além das formalidades jurídicas.

Vale lembrar que na história recente deste século, um tema volta a rondar as esferas midiática, política e jurídica do país, "a questão" do negro brasileiro. Com ele, a inevitabilidade de se lembrar de uma gama de subtemas como a escravidão, a abolição da escravatura, a República, o legado para os libertos depois de mais de 350 anos de cativeiro, a cultura do silêncio e as reações. O rompimento do discurso de igualdade entre brancos e negros ganhou força depois que $\mathrm{o}$ afrodescendente chegou às páginas mais nobres dos jornais, pautados pela declaração pública do governo brasileiro em território africano de que havia racismo no Brasil. ${ }^{3}$ Em seguida, deu-se início a implantação das políticas públicas de caráter afirmativo. E com estas, a emergência de lutas que durante séculos se mantiveram como memória subterrânea ${ }^{4}$, tão antigas quanto a opressão de milhões ${ }^{5}$ de humanos em diáspora.

\footnotetext{
${ }^{3}$ A declaração do governo brasileiro aconteceu durante a Conferência Mundial contra o Racismo, a Discriminação Racial, a Xenofobia e Formas Correlatas de Intolerância, promovida pela ONU, em Durban, na África do Sul, em 2001.

${ }^{4}$ A memória subterrânea para Michael Pollack (1989) é uma estratégia de trabalhar as lutas individuais e coletivas, enquanto se espera o momento histórico adequado para fazer emergir as reivindicações. Em Memória, Esquecimento e Silêncio, o autor afirma que a fronteira dos silêncios e não-ditos com o esquecimento total não se fecham, ao contrário, vivem em constante deslocamento. Pollack (idem) argumenta que existe uma vivacidade das lembranças individuais e de grupos. "Opondo-se à mais legítima das memórias coletivas, a memória nacional, essas lembranças são transmitidas no quadro familiar, em associações, em redes de sociabilidade afetiva e/ou política." (POLLACK, 1989, p.6).

${ }^{5}$ Durante parecer em depoimento, realizado em Brasília, em março de 2012, acerca da Arguição de Descumprimento de Preceito Fundamental - ADPF/186, apresentado ao Supremo Tribunal Federal, Luiz Felipe de Alencastro afirma que "na realidade, nenhum país americano praticou a escravidão em tão larga escala como o Brasil. Do total de cerca de 11 milhões de africanos
} 


\section{Observatório}

ISSN n² 2447-4266

Vol. 4, n. 3, maio. 2018

DOI: https://doi.org/10.20873/uft.2447-4266.2018v4n3p783

A proposta do trabalho é refletir sobre instrumentos utilizados pela mídia brasileira que invisibiliza uns em detrimento de outros, como a memória ou o esquecimento. Para tanto, narrativas do século XIX serão observadas, em confrontação com ações políticas do século XXI, como as ações afirmativas. Não se trata de comparação, considerando que cada período tem seu próprio contexto, mas de um diálogo entre comunicação e história, um certo deslocamento para saber como os discursos se dão nos dois períodos. Enquanto que no século $X I X, O$ discurso era da imprensa, na contemporaneidade, a narrativa é marcada pela midiatização, ou como teoriza Sodré (2012), estarmos na era do "bios virtual", caracterizado por uma nova forma de existência, cuja centralidade é a mídia. O desafio é desnudar o senso comum do "lugar" atribuido ao afrodescendente e ressaltar a relevância da "ocupação de lugar", temo empregado por Sodré para marcar a importancia da ocupação de espaço, cuja referência nas palabras do autor, pode ser topográfica ou topológica. No primeiro caso, seria a ocupação territorial de espaço; no segundo, a lógica das articulações de lugar. (SODRÉ, 2014).

\section{A mídia e o esvaziamento simbólico do afrodescendente}

No século XIX, a Campanha abolicionista, que prometia ser uma ruptura, trazendo em si a presença das singularidades do brasileiro, se transformou em um ato formal e não tardou a ser esquecido pela imprensa. No pós abolição, o afrodescendente foi periferizado e silenciado. Logo, o que se seguiu ao longo

deportados e chegados vivos nas Américas, 44\% (perto de 5 milhões) vieram para o território brasileiro num período de três séculos (1550-1856)." (ALENCASTRO, 2010, p.1). 


\section{Observatório}

ISSN n² 2447-4266

Vol. 4, n. 3, maio. 2018

DOI: https://doi.org/10.20873/uft.2447-4266.2018v4n3p783

do século XX, parafraseando Rancière ${ }^{6}$, foi ver o homem ser substituído pelo discurso sobre o homem. Nesse instante estava instalado o esvaziamento do sujeito enquanto tal, e em seu lugar emergiram as diversas análises em torno do negro no Brasil, como "formação das três raças", "democracia racial", exotismo da raça, e outros. O país que, em dado momento, acolheu a partilha pública da experiência do outro, por falta de um projeto contra-hegemônico ou mesmo de uma sociedade civil, como a compreende Gramsci, se fecha e opta pela construção de um projeto de nação, sem representatividade e vazio para o sujeito em referência. Segundo Marcelo Paixão (2014), nesse projeto de nação, a população negra não era contemplada.

$\mathrm{Na}$ civilização ocidental é usual as pessoas serem identificadas pela cor da pele, independentemente da classe social. Contudo, os sujeitos do grupo dominante, como diz Lorenzi-Cioldi (2002), concedem a cada um dos seus membros atributos de sua personalidade, disseminam sentimento de liberdade diante da estrutura social e não se assumem como grupo. Ao indivíduo branco são dispensadas as referências biológicas, ele não é identificado como "homem branco", "mulher branca" ou "criança branca." Já ao individuo negro, a cultura em voga dispensa o "homem", sendo a referência substituída pelo vocábulo negro/a, que, por sua vez, assume a função principal na sentença, vira sujeito. Mesmo em caso de elogio, ainda assim, os tratamentos de distinção não são dispensados. Não é incomum ouvir a fala sobre uma mulher negra que esteja passando na rua, estampada em uma capa de revista (não tão usual fora do período de carnaval) ou na televisão: que "negra bonita!" Ora, nessa expressão a

\footnotetext{
${ }^{6}$ Em entrevista à Revista Cult, Rancière explica que o vazio na obra de arte pode ser visto sob diferentes ângulos. Um deles seria a utilização conceitual em que se substitui a obra pelo discurso sobre a obra. Edição 139 da Revista Cult. (RANCIÈRE, 2009, p. 20).
} 


\section{Observatório}

ISSN n² 2447-4266

Vol. 4, n. 3, maio. 2018

DOI: https://doi.org/10.20873/uft.2447-4266.2018v4n3p783

primeira coisa que se observa é a destituição da existência do sujeito. Há uma negação da mulher, assim como do homem. A pessoa passa a ser apenas uma cor.

Fazendo analogia com o século XIX, o africano que chegava ao Brasil, compulsoriamente, era escravizado, destituído de direitos, de alma, de família, de sentimento, de subjetividades. Tinha valor de mercadoria e era identificado apenas como escravo. Naquele momento, perdia a condição de humano. Não era homem, nem mulher, nem criança, somente escravo. Na prática das relações era comum usar outra palavra, simplesmente para não falar o nome do sujeito. Este era chamado de "boi zebu", "coisa ruim", "capeta", "miserável", "peste", "coisa feia", "maldito" e tantas outras variantes. Para usar termo de Roland Barthes, trata-se de uma prática de exnominaçao ${ }^{7}$ do negro na sociedade, da construção de significado no âmbito dos tabus. Como observa Guérios, "as palavras exteriorizadas podem ter forças sobrenaturais benéficas ou maléficas, porém há palavras que não devem ser exteriorizadas, a fim de se evitarem malefícios dos mesmos poderes. Estes vocábulos são tabus." (GUÉRIOS, 1979, p.01).

Considerando que toda linguagem é carregada de ideologia, pode-se afirmar que a invisibilização do afrodescendente ocorre já na origem da formação cultural brasileira. Frantz Fanon (2008) avalia a violência sofrida pelo colonizado como algo que implica consequências da ordem da psiquê (alma). De acordo com o autor (2008), o negro na sua casa não precisava "confirmar

\footnotetext{
${ }^{7}$ De acordo com o Oxford Dictionary of Media and Communication, "exnomination" é um termo de Barthes, usado para o fenômeno por meio do qual a burguesia escondia o nome do indivíduo (e a identidade), não se referindo a ele próprio como tal. Trad. Livre: "Barth's term for the phenomenon whereby the bourgeoisie hides its name (and identity) by not referring to itself as such [...]." (CHANDLER, Daniel; MUNDAY, Rod, 2014, online).
} 


\title{
Observatório
}

seu ser diante de um outro". (FANON, 2008, p. 104). Em diáspora, o africano perde suas referências, seus costumes são ignorados e este se vê diante de uma realidade fortemente hierarquizada, uma civilização que não conhece e que arbitrariamente fará parte da sua vida.

\begin{abstract}
Existe o momento de 'ser para-o-outro', de que fala Hegel, mas qualquer ontologia torna-se irrealizável em uma sociedade colonizada e civilizada. Parece que este fato não reteve suficientemente a atenção daqueles que escreveram sobre a questão colonial. Há na weltanschauung de um povo colonizado, uma impureza, uma tara que proíbe qualquer explicação ontológica. Pode-se contestar, argumentando que o mesmo pode acontecer a qualquer indivíduo, mas, na verdade, está se mascarando um problema fundamental. A ontologia, quando se admitir de uma vez por todas que ela deixa de lado a existência, não nos permite compreender o ser do negro. Pois o negro não tem mais de ser negro, mas de sê-lo diante do branco. [...] aos olhos do branco, o negro não tem resistência ontológica. (FANON, 2008, pp. 103-104). ${ }^{8}$
\end{abstract}

Sem condição de existencia interna e externa, o africano escravizado sofre todo tipo de opressão, a fim de perder a humanidade. A violência praticada antes e durante o processo do tráfico e da escravidão foram estruturadas de tal modo que ultrapassam o fim da escravidão, permeando a contemporaneidade. Bóris Fausto (2007) considera que "o preconceito contra o negro [...] chegou modificando os nossos dias". (FAUSTO, 2007, p. 69).

A exnominação do negro, a negação da sua subjetividade traz prejuízo não apenas para os indivíduos afetados, mas para toda a sociedade. Contraditoriamente, esse mesmo não-sujeito construiu o Brasil em diversos campos da cultura, da arte, da agricultura, da engenharia, condição não reconhecida até os días atuais. A utilização de técnicas desconhecidas pelos

\footnotetext{
${ }^{8}$ Na obra A ideia de justiça em Hegel, Salgado (1996) esclarece: "o ser-para-si é, no sentido que lhe é dado na estruturação do pensamento na Lógica, o ser que sabe de si mesmo, portanto um $e u$, ao passo que o ser-aí é um ser para o outro, tal como a natureza que tem o seu ser-aí para o outro, para o espírito que sabe de si, que é para si." (SALGADO, 1996, p. 122).
} 


\section{Observatório}

ISSN n² 2447-4266

Vol. 4, n. 3, maio. 2018

DOI: https://doi.org/10.20873/uft.2447-4266.2018v4n3p783

portugueses é um exemplo. Os africanos trazidos compulsoriamente ao Brasil possuíam conhecimento da agricultura, metalurgia do ferro, técnicas de cura (Reino do Congo), trabalho com pedra, e invenção da cerâmica, além das "técnicas militares baseadas no poder dos arqueiros, que permitiram à cidade manter os vizinhos mais poderosos a distância e dominar os mais vulneráveis". (FIGUEIREDO, 2011, p. 69).

Para Nei Lopes, excluir, negar e não referenciar o africano ou seu descendente, mesmo que este tivesse papel importante no Brasil, fazia parte da estratégia da cultura dominante.

Essa ocultação das origens africanas de grandes vultos nacionais, associada à falta ou falsificação de suas iconografias, inclusive por fotografias retocadas, contribuiu lamentável e fatalmente para o desconhecimento sobre o peso real da contribuição de intelectuais, artistas e técnicos pretos e mulatos na formação da cultura brasileira ao longo dos anos. (LOPES, 2010, p. 96).

Segundo o autor (2010), é comum encontrar em publicações referências a condição de 'negro' no Brasil como definidora de uma categoria social e não de uma identidade ou de um reconhecimento do sujeito singular. "Os 'grandes homens', nessas publicações, quando afrodescendentes e pobres, são mencionados apenas como 'nascidos em lar humilde' e não em sua dimensão étnica." (LOPES, 2010, p. 96). Observamos que, de um lado, a pobreza no Brasil ocupou um elevado índice nos indicadores sociais ao longo dos séculos e, de outro, o mais significativo autor dos estudos teóricos acerca das lutas de classe e relações de trabalho, Karl Marx, não contemplou em seus escritos as relações raciais. Desse modo, o enquadramento de identificação das relações e práticas sociais gira em torno de classes, e tudo o que foge a essa classificação se torna externalidades. 


\section{Observatório}

ISSN n² 2447-4266

Vol. 4, n. 3, maio. 2018

DOI: https://doi.org/10.20873/uft.2447-4266.2018v4n3p783

Nei Lopes (2010) discorre sobre diversas personalidades negras na cultura brasileira. Apresenta personalidades de destaque nas áreas das Artes plásticas e visuais, Música de concerto e popular, Artes Cênicas, Arquitetura, Letras, Política, Direito, Jornalismo, Engenharia, Geografia e História, Medicina e Academia. Cita, entre outros, nomes como Aleijadinho, Padre José Maurício, Carlos Gomes, Gonçalves Dias, Machado de Assis, Lima Barreto, Cruz e Souza, Luiz Gama, José do Patrocínio, Teodoro Sampaio, André Rebouças, Juliano Moreira, Nilo Peçanha, Rodrigues Alves e Barão de Cotegipe. São atores sociais integrantes da História de séculos passados, no entanto não aparecem na composição "da grande História do Negro no Brasil" (LOPES, 2010, p. 132), ainda a ser contada.

No passado, o encobrimento da população negra era ainda mais radical e o objetivo, lá, como cá, passa pelo econômico. Quando se deu a abolição da escravatura, na realidade, já havia poucos escravizados, cerca de $5 \%$ da população, como indicam historiadores (Fausto, 2007; Costa, 2007; Carvalho, 2012). E no interior da sociedade existia, de longa data, a história de luta e de resistência do povo negro contra a opressão. No Brasil Império, intelectuais negros, seja pelas letras, seja pelo movimento político, ou pelo jornalismo, e as artes, de forma mais ativa ou mais tímida, faziam parte do bloco de luta. Eram articulações seminais para a constituição do movimento negro, que vai surgir no final dos anos 70 do século XX, com esta denominação. Com a República, alguns perderam espaço ${ }^{9}$, mas ainda assim lutaram para se fazer reconhecer

\footnotetext{
${ }^{9}$ No início da República, os abolicionistas negros que mais se engajaram na luta, como o jornalista José do Patrocínio e o engenheiro André Rebouças, basicamente saíram de cena. Rebouças partiu do Brasil, acompanhando a família Imperial, mas com a morte do Imperador D. Pedro II, acabou indo para a África do Sul, onde, deprimido, teria se suicidado. José do
} 


\section{Observatório}

ISSN n² 2447-4266

Vol. 4, n. 3, maio. 2018

DOI: https://doi.org/10.20873/uft.2447-4266.2018v4n3p783

como sujeitos históricos. A luta pela liberdade efetiva se prolonga por todo o século XX e XXI, contra a prática do racismo que, como afirma Cuti, "desagrega a sociedade e impede seu potencial humano de se manifestar plenamente. E o Brasil precisa de coesão do seu povo para ter equilíbrio social e prosperidade sustentável." (CUTI, 2010, p.6).

Naturalmente que cada tempo histórico traz consigo suas próprias questões. As diferenças são incontáveis, tanto nas relações sociais como do ponto de vista do poder político e econômico. Podemos perguntar o que tem em comum o século XIX com o século XXI? Ora, se no final do XIX a prática das relações inter-raciais era pela exnominação, pela negação de pronunciar o simples nome do sujeito, após a abolição, o afrodescendente livre foi silenciado pela invisibilidade do Estado e da mídia, esta atuando em estreita conexão com o poder instituído. Em ambos os séculos, o racismo, de raízes no capitalismo, se esconde, se camufla, se fortalece e se manifesta, tanto para viabilizar um projeto de Nação de caráter eurocêntrico, quanto diante da mais simples situação de desconforto ou ameaça de perder o status quo, como ocorreu com o advento das cotas. Também nos dois períodos o discurso da imprensa e da mídia insiste em encobrir o sujeito histórico.

Ora, a representação do afro-brasileiro pela mídia aparece como um lugar de pertencimento pré-definido e reforçado por estereótipos. A partir das ações afirmativas no Brasil e o sistema de cotas, o discurso se intensifica, é veiculado como "cotas da discórdia", da "divisão do país em raças", etc. Tal narrativa revela a construção de um lugar simbólico para o negro, como desejo

Patrocínio ficou isolado, "além de ser banido das hostes republicanas também estava sendo vigiado. E isso fazia com que se retraísse cada vez mais." (ALVES, 2009, p. 252). 


\section{Observatório}

de verdade, imposto pela negação, pelo esquecimento, pelo silêncio. $O$ discurso do passado está colado ao presente por meio de estereótipos e pela mentalidade moral da definição de um topos, lugar do outro. O discurso conservador de construção de um ethos da identidade nacional é reforçado por alianças entre o capital, a globalização e o poder. Podemos afirmar que o envelope que reveste e transporta tal conteúdo é a mídia.

Para Sodré, "[...] a identidade cultural/nacional é uma das principais questões - senão a principal - que marcam fortemente a história intelectual do país". (SODRÉ, 2000, p. 9). O negro, mesmo com o fim da escravidão, é reificado, estereotipado, silenciado e, independente da formação, esbarra na cultura patrimonialista da suposta superioridade branca dominante, o que retira do sujeito o direito de oportunidades e de mobilidade social. Tanto na Colônia como no Império a educação superior reproduzia a

[...] centralização e homogeneização da formação das elites. [...] Menciona-se, por exemplo, a presença de estudantes de cor já nos primeiros anos da Escola de São Paulo ${ }^{10}$, aos quais, por sinal, um dos professores se recusava a cumprimentar alegando que negro não podia ser doutor (CARVALHO, 2006, pp. 74-75).

As narrativas da imprensa naquela época falavam de humanidade, mas não com a intenção de tornar o escravizado cidadão participante, e sim com o objetivo de libertar o país do que representava a escravidão, um atraso, portanto, um impeditivo de modernização. Também no XXI, a negação midiática é de reconhecimento do sujeito real, a partir, por exemplo, do

\footnotetext{
${ }^{10}$ Na Escola de São Paulo foi criado o curso de Direito em 1827, e iniciado em 1828. (Cf. "A construção da ordem / Teatro das sombras", de José Murilo de Carvalho, 2006).
} 


\section{Observatório}

ISSN n² 2447-4266

Vol. 4, n. 3, maio. 2018

DOI: https://doi.org/10.20873/uft.2447-4266.2018v4n3p783

discurso de classe. Porém, há uma diferença fundamental a se ressaltar entre essas duas situações, qual seja o desenvolvimento do que Gramsci chamou de "sociedade civil, enquanto traço específico de sua manifestação nas sociedades capitalistas mais complexas." (COUTINHO, 2007, p. 131). De acordo com Carlos Nelson Coutinho, Gramsci "afirma ser a sociedade civil uma característica distintiva das sociedades onde existe um grau elevado de socialização da política, de auto-organização de grupos sociais." (COUTINHO, idem). Se no XIX, a sociedade civil era incipiente, na contemporaneidade ampliam-se as arenas de disputa.

Porém, a despeito de maior organização e independencia, a sociedade civil na contemporaneidade também não dá conta do racismo, mesmo porque o apagamento do afro-brasileiro é resultado da ideologia branca racista, cujo projeto social já não precisa mais estabelecer pacto algum, porque a dominação criou raizes, com forte contribuição midiática. Não depende mais do aval da ciência e nem demanda mais da igreja o atestado de isenção de culpabilidade cristã pela violência praticada contra os povos africanos e descendentes, considerados sem alma. Fanon (2008), nas análises do processo de dominação, chega a afirmar que a violência da colonização atua no consciente $e$ inconsciente, tornando a sociedade patológica. A dominação é simbólica, de construção discursiva, tornando mais difícil a identificação e o combate. $O$ autor atesta que "a civilização branca, a cultura europeia, impuseram ao negro um desvio existencial" (FANON, 2008, p. 30), o que provoca sofrimento. Contudo, as reações se reinventam. Os movimentos negros sociais são os mais antigos do 


\section{Observatório}

ISSN n² 2447-4266

Vol. 4, n. 3, maio. 2018

DOI: https://doi.org/10.20873/uft.2447-4266.2018v4n3p783

Brasil, como lembra o historiador Joel Rufino ${ }^{11}$. Com adaptações a cada época, no passado e no presente, há ativistas em diversas frentes - na academia, nos sindicatos, nos encontros, nas redes sociais, nos procesos culturais. A implantação das Ações afirmativas, na modalidade de cotas, é um exemplo de reivindicações dos movimentos negros por educação e reconhecimento, em encontros realizados em nível regional e nacional.

\section{"Excesso de memória, excesso de esquecimento"}

Para o historiador Joel Rufino dos Santos "a história da escravidão no Brasil é a história da luta contra a escravidão". (SANTOS, 2010, p. 14). Vejamos a narrativa do Jornal Gazeta de Notícias, no século XIX, acerca da Campanha abolicionista. Na publicação do dia 28 de setembro de 1880, na terceira página, coluna Comunicado, o periódico divulga, na íntegra, o "Manifesto da Sociedade Brasileira contra a Escravidão". O documento, endereçado ao "País", relata os maus tratos dispensados aos cativos, critica os políticos de desejarem perpetuar o sistema de escravidão e convida o Partido Liberal a ser algo "[...] mais do que o grande cliente submisso da grande propriedade rural [...]". Acusa os políticos de indiferentes. "Os atuais escravos, um milhão e meio de homens! [...] $O$ Parlamento não os enxerga. Pairando nas alturas, ele só vê, na extensão do país, a casa do senhor, não descobre a senzala dos escravos." (GAZETA DE NOTÍCIAS, 28 de set. de 1880 , p. 3). Contudo, com um olhar mais atento é possivel

\footnotetext{
${ }^{11} \mathrm{O}$ autor esclarece que existe uma luta organizada contra o racismo que parte de uma luta maior, que seria a "democracia não na acepção que lhe dão, em geral, os políticos e os jornais, mas de um processo interminável de ajustamento de contradições, acerto de diferenças, negociação sem fim de lugares sociais." (SANTOS, 2010, p. 36).
} 


\section{Observatório}

ISSN n² 2447-4266

Vol. 4, n. 3, maio. 2018

DOI: https://doi.org/10.20873/uft.2447-4266.2018v4n3p783

perceber que mesmo no manifesto, a defesa do africano e afro-brasileiro não era em função do homem em si, não tinha uma dimensão ética, mas visava claramente a boa imagem do Brasil junto às demais nações.

Quando um brasileiro leva o nosso nome à Europa; quando a proteção concedida aos sábios europeus mostra a nossa cultura intelectual; quando nas nossas relações exteriores aparecemos como um pais adiantado, generoso e liberal, o nosso amor próprio se satisfaz e se estimula. Pois bem, pode uma nação assim, inteligente, sensível e cheia de incentivos próprios, assistir indiferente ao atraso revoltante em que a escravidão a mantém em relação ao mundo inteiro? (GAZETA DE NOTICIAS, 28 de set. de 1880, p. 3).

O manifesto diz textualmente: "o que temos em vista porém, não é só a libertação do escravo, é a libertação do país; é a evolução do trabalho livre que se há de fazer sob a responsabilidade da geração atual.". (GAZETA DE NOTÍCIAS, 28 de set. de 1880, p. 3). Ao que afirma em seguida: "Não queremos desconhecer nenhuma das nossas obrigações, repudiar nenhum dos nossos deveres." (GAZETA DE NOTÍCIAS, idem). Ora, a obrigação da Sociedade seria a emancipação por si só? Que deveres foram cumpridos após o 13 de maio de 1888? Diz o texto que a Sociedade está aberta a todos, convidando tanto os proprietários agrícolas a se engajarem na luta contra a escravidão, como o governo a assumir a liderança do movimento. Observa que o Brasil é uma exceção no continente, ao manter a escravidão como organização social e a monarquia como organização política.

Com a queda desses dois tipos de organizações (social e política), aparentemente a incoerência teria sido resolvida, seguindo a máxima de que "um país se redefine sem cessar". (SANTOS, 2010, p. 13). No entanto, após a abolição, e com o advento da República, os recém libertados adquirem outro 


\section{Observatório}

ISSN n² 2447-4266

Vol. 4, n. 3, maio. 2018

DOI: https://doi.org/10.20873/uft.2447-4266.2018v4n3p783

status, o de "lugar de memória"12 para usar conceito de Pierre Nora, historiador francês, que o criou com o fim de analisar a questão nacional francesa na sua complexidade entre memória e história. O autor observa que só "há lugares de memória porque não há mais meios de memória." (NORA, 1993, p. 7). Trazendo para o caso brasileiro em análise, a partir da efetivação do ato de libertação dos escravizados, o sujeito, objeto da luta, desaparece de cena e a liberdade "experimentada" na República pode ser lida como um lugar de esquecimento.

A memória é a vida, sempre carregada por grupos vivos e, nesse sentido, ela está em permanente evolução, aberta à dialética da lembrança e do esquecimento, inconsciente de suas deformações sucessivas, vulnerável a todos os usos e manipulações, susceptível de longas latências e de repentinas revitalizações. (NORA, 1993, pp.8-9).

Desse modo, a memória do afrodescendente é reduzida a um objeto, perdendo a dimensão simbólica, porque sua luta pela liberdade, quando lembrada, aparece tão somente como "lugar de memória", não como sujeito de memória. Na realidade, seria mais apropriado afirmar que a liberdade do afrobrasileiro foi resumida à um evento, aquele realizado no passado, portanto histórico, e se encerrou com o cumprimento do objetivo da Campanha abolicionista, de pôr fim a um sistema de governo atravessado por um modelo arcaico, em desacordo com os ideias liberais do capitalismo emergente. A liberdade efetiva ficou na promessa dos políticos abolicionistas e do Império brasileiro. Na República, o que se evidencia é uma distancia enorme entre o direito formal e o direito de fato, o real.

\footnotetext{
${ }^{12}$ De acordo com Pierre Nora "os lugares de memória são, antes de tudo, restos. A forma extrema onde subsiste uma consciência comemorativa numa história que a chama, porque ela a ignora. É a desritualização de nosso mundo que faz aparecer a noção." (NORA, 1993, pp. 12-13).
} 


\section{Observatório}

ISSN n² 2447-4266

Vol. 4, n. 3, maio. 2018

DOI: https://doi.org/10.20873/uft.2447-4266.2018v4n3p783

$\mathrm{Na}$ realidade contemporânea, salta aos olhos o silenciamento da imprensa, como uma construção hegemônica, ancorada na força do pensamento único de uma nação idealizada. Nesse processo, à população negra são dispensadas narrativas estereotipadas e negadas participar de qualquer espaço de voz. Fechado aos meios de comunicação, aos bens materiais e imateriais, e sem mobilidade social, o afrodescendente se torna invisível, em amplas fronteiras. Os efeitos da colonização são imensos. Vale lembrar um episódio ocorrido em 1996, durante visita do presidente da Argentina, Carlos Menem, aos Estados Unidos. Na ocasião, este declarou à imprensa local que em seu país não havia negros e que essa era uma realidade do Brasil. O discurso revela a crença na construção histórica de uma cultura, do mesmo modo que ratifica o sentimento de exclusão. Na Argentina, a declaração causou reações. "Nós somos aqueles que não têm identificação. Cada vez somos mais brancos e são poucos os que sabem que são filhos de negros. $E$ aquele que sabe quer esconder esse fato." (LA MADRID, 2011).

A partir desse episódio, La Madrid fundou a organização África Vive, com o fim de reunir afro-argentinos dispostos a lutar contra a discriminação, por emprego e oportunidade de educação na comunidade negra, combater a pobreza e imprimir na história de seu país um novo conceito de cultura, no qual o/a negro/a possa ter autoria e visibilidade. Assim como no Brasil, negação e invisibilidade são conceitos comuns no país, no entanto, tem gerado confusão e estranhamento até mesmo entre os pares, como esclarece Domínguez.

[...] em alguns casos, o termo 'afro' é utilizado como sinônimo de 'africano', mas em outros refere-se à especificidade latino-americana. Essa especificidade liga-se ao fato de que os afro-descendentes, na 


\section{Observatório}

ISSN n² 2447-4266

Vol. 4, n. 3, maio. 2018

DOI: https://doi.org/10.20873/uft.2447-4266.2018v4n3p783

América Latina, além de serem 'negros', em países onde o 'branqueamento' populacional fez parte do ideal civilizatório, partilham a memória de ser descendentes de escravos e também o fato de terem sido marginalizados socialmente nas diferentes histórias nacionais. (DOMÍNGUEZ, 2004, p. 140)

A autora acrescenta que "[...] enquanto no imaginário portenho a 'raça negra' é atributo da 'brasilidade', os negros, sejam do país que forem e mesmo se argentinos, são muitas vezes identificados como brasileiros." (DOMINGUEZ, 2004, p. 140). Tal afirmativa pode ser lida como um exemplo de folclorização, considerando a força da agenda nacional do carnaval carioca e baiano. $\mathrm{Na}$ realidade, independente de serem argentinos, africanos de qualquer país do continente em diáspora ou brasileiros, os afrodescendentes são estereotipados pela cor da pele, pela tentativa de morte da cultura, pela dominação e pela insistência em desumanizar o sujeito. Como diz Sodré (2000 p, 358), o senso comum é que em qualquer lugar "[...] o negro é exótico, como um animal a ser observado [...]".

Se no Brasil, a luta dos negros contra a opressão é considerada por intelectuais (Santos, 2010; Sodré, 2012) como uma das lutas sociais mais antigas, no país vizinho, a organização África Vive reage a estereótipos e a invisibilidade do negro, praticada pelo governo e pela imprensa, a partir de uma agenda de atividades coletivas, inserções em jornais, e até um senso particular, a fim de contribuir para mudar a história oficial acerca da população afro. Em ambos os países, o movimento de pressão torna dialética a dinâmica da negritude, gerando condições de possibilidades e confirmando a crença de Durkheim de que "[...] uma vez que a organização da mentalidade coletiva existe, é susceptível de reagir sobre sua causa e contribuir para modificá-la." 


\section{Observatório}

ISSN n² 2447-4266

Vol. 4, n. 3, maio. 2018

DOI: https://doi.org/10.20873/uft.2447-4266.2018v4n3p783

(DURKHEIM E MAUSS, 1981, p. 419), A falta de espelho para se ver e a seus ancestrais, torna a luta um desafio cotidiano, sobretudo quando o que reflete são modelos europeus.

Essa memória histórica explica a ideia difundida acerca da inexistência de negros na Argentina, a partir de processos de apagamentos ou silenciamentos simbólicos. Nos dois países, e em muitos outros de histórias semelhantes, são adotados mecanismos de manipulação. "O cerne do problema é a mobilização da memória a serviço da busca, da demanda, da reivindicação de identidade." (RICOEUR, (2007, p. 94). Segundo o autor, os sintomas variam como "[...] excesso de memória, em tal região do mundo, portanto, abuso de memória insuficiência de memória, em outra, portanto, abuso de esquecimento." (RICOEUR, idem). Tal premissa se aplica as sociedades colonizadas, cuja esfera dominante ocupa todos os espaços possíveis, restando à esfera dominada apenas a subalternização, a sobrevivência. A opressão sustenta a lógica dessa prática e oculta reações.

Com isso, vai se formando no imaginário popular a história contada e apresentada como verdade. No caso da sociedade brasileira, sabemos que a estrutura da nação foi construída com base na crença de ausência de conflitos raciais, embora as portas fossem franqueadas aos brancos, e cerradas aos negros. Mesmo na contemporaneidade, mantem-se vigente o argumento, em grande parcela da população, de que a ascensão social independe da cor da pele. Os chamados intérpretes do Brasil, como Gilberto Freyre, contribuíram para essa noção. Como diz Emilia Viotti da Costa, "Freyre argumentava que a distância social, no Brasil, fora o resultado de diferenças de classe, bem mais do que de preconceitos de cor ou raça." (COSTA, 2007, p. 367). 


\section{Observatório}

ISSN n² 2447-4266

Vol. 4, n. 3, maio. 2018

DOI: https://doi.org/10.20873/uft.2447-4266.2018v4n3p783

Tais argumentos pressupunham que havia no país uma certa democracia racial e justificava, alegando que "[...] como os negros brasileiros desfrutavam mobilidade social e oportunidades de expressão cultural, não desenvolveram uma consciência de serem negros da mesma forma que seus congêneres norteamericanos." (COSTA, 2007, p. 367). A miscigenação, apontada por Freyre, como solução para "[...] escapar dos problemas raciais que atormentavam os norteamericanos" (Idem), na realidade, fazia parte do projeto de branqueamento do país. E ao contrário de Freyre, compreendemos que a distância social no Brasil faz parte de uma construção histórica do desejo de vontade de eliminar a população negra, quer seja pela carência de condições de possibilidade de viver, que seja pelo encobrimento, ou morte simbólica.

No Brasil, na Argentina, no Peru ou em tantos outros países, o racismo e a discriminação encarregam-se de destruir a $\operatorname{arkhé}^{13}$, deixando marcas no espírito, abalando a confiança em si próprio, o que muitas vezes leva a vítima, como lembra Fanon (2008), a desejar ser branca. Tal prática não se dá sem resistência, como ilusta a parábola contada pelo autor. Fanon conta que estavam no trem um jovem negro, uma criança branca e ele. O negro tremia de frio, a branca tremia de medo do negro, porque achava que ele era mau e que iria destruí-la e ele tremia de raiva. A lógica do racismo pode ser comparada a lógica do capitalismo, que para sobreviver precisa produzir miséria; do mesmo

${ }^{13}$ A arkhé é definida como "a origem autêntica, os fundamentos do sentido" (SODRÉ, 2005, p.15), mas também destino, futuro, construídos pelo vínculo. Também é chamada de cultura de arkhé, de dimensão simbólica e sua prática, como a liturgia, é um meio de sobreviver à violência e de se relacionar entre si e em grupo. Contudo, na realidade da população negra, tal força logo é percebida e perseguida pelo poder branco. "Se a criação dos terreiros significou a busca de um território onde se pudesse reenraizar a Arkhé negra após a diáspora africana, a repressão a esses espaços e às suas formas de sociabilidade correspondia a um projeto de desagregação e desestruturação daquele sistema simbólico." (COUTINHO, E. 2014, p. 60). 


\section{Observatório}

ISSN n² 2447-4266

Vol. 4, n. 3, maio. 2018

DOI: https://doi.org/10.20873/uft.2447-4266.2018v4n3p783

modo, a sobrevivência da dominação branca está no controle da consciência, no controle do saber, daí a educação fazer parte de uma elite. Não por acaso, no Brasil ou na Argentina os campi das principais universidades, norteadores de condições de possibilidades em diversos campos do saber e do poder, continuam vazios de diversidade. Existem como territórios historicamente carentes da pluralidade étnico/racial, da diversidade de culturas tão presentes na gênese das grandes descobertas (?) das Américas. Logo, o silenciamento faz parte de uma estrutura, cujos seguidores contam com a colaboração da imprensa e da disseminação da verossimilhança.

Se a (des)construção das relações raciais constitui uma questão, considerando a inexistência cientifica da raça, e ao mesmo tempo sua ratificação na cultura histórica dos países, supomos que a esfera da educação, como uma ordem de sociabilidade e trocas simbólicas, se faz urgente, radical, a despeito de ser um espaço de branco, pensado para branco e mantido como tal. Afinal, "[...] incluir como sinônimo de abrir as portas, sem gerar condições para o acesso democrático de todos os jovens ao saber, é avançar apenas na retórica da hipocrisia pública. 'Inclusão' revela-se, no fundo, como um tênue vestígio da democratização do saber." (SODRÉ, 2012, p. 246).

Certamente, acabar com o racismo demanda mais que educação. O combate à prática está relacionado ao campo da memória. Ou seja, vincula-se a construção de sentidos, a exposição cotidiana do tema, por meio de questões históricas, com passado e presente latentes, sendo a lembrança de um o aprendizado do outro. Acreditamos no potencial do enfrentamento cotidiano, do tensionamento e da reflexão como instrumentos capazes de viabilizar a compreensão e levar à modificações, gerando abertura à novas experiências. 


\section{Observatório}

ISSN n² 2447-4266

Vol. 4, n. 3, maio. 2018

DOI: https://doi.org/10.20873/uft.2447-4266.2018v4n3p783

Contudo, as narrativas da imprensa vem optando desde o final do século XIX pela naturalização das diferenças entre brancos e negros, cristalizando um lugar para ambos, reduzindo os estranhamentos e levando à reprodução de um senso comum dado. Desse modo, reorienta a opinião pública, transformando suas narrativas em realidade. Mergulhada em uma dinâmica de esquecimento, a imprensa, no caso do afrodescendente, age como se também esquecesse que as "[...] mudanças são constantemente geradas por contextos sociais diversos, que associam e selecionam o passado para preencher o presente de sentido e configurar o futuro." (RIBEIRO; BRASILIENSE, 2007, pp. 220-221).

Da abolição da escravatura ao século XXI, o futuro do negro brasileiro confundiu-se com o seu passado. A liberdade prometida e garantida por Lei, ficou na Lei e na promessa. Enquanto isso, o homem concreto, objeto da Campanha abolicionista tornou-se invisível, emergindo um ideal de branqueamento como solução para os problemas do país. "Por isso, o horizonte ético da mestiçagem latino-americana desenha-se como uma espécie de atenuação biológica da distância entre peles claras e escuras, ou seja, uma raça 'terceira.'" (SODRÉ, 2000, p. 193).

Cercado de estereótipos e imersos na prática mnemónica do esquecimento, tanto pelo governo como pela imprensa, o afrodescendente passa da condição de invisível para sujeito real na primeira década do século XXI, a partir da implantação das políticas públicas de ações afirmativas. Ganha as primeiras páginas dos jornais, não mais como bandido, suspeito, exótico, nem como sambista ou jogador de futebol, mas como sujeito que reivindica o direito de frequentar o ensino público superior. Trata-se de uma luta antiga por reconhecimento e educação, cujo resultado é a declaração por parte do 


\section{Observatório}

ISSN n² 2447-4266

Vol. 4, n. 3, maio. 2018

DOI: https://doi.org/10.20873/uft.2447-4266.2018v4n3p783

governo brasileiro da necessidade de combate ao racismo e início das ações afirmativas, na modalidade de cotas em universidades públicas, sendo a UERJ a primeira a adotar a medida. Uma prática contra-hegemônica? Segundo Ribamar Bessa $(2015)^{14}$, as cotas podem ser revolucionárias, se os alunos interferirem no currículo escolar. Como se sabe, a universidade é branca, o ensino é branco e a bibliografía é eurocéntrica.

\section{Considerações finais}

Como se pode inferir, a narrativa em torno da população negra, seja no século XIX, seja no XXI gira em torno da invisibilidade. Se em um período, o objetivo era libertar o país do jugo do escravidão, como apontam historiadores (Fausto, 2007; Carvalho, 2006; Viotti, 2007, etc), e não necesariamente uma preocupação com o escravizado em si, no XXI, o cuidado é com o não-discurso, ou seja, tornar invisivel o afrodescendente, de tal modo que ele se torne um não sujeito. Pelo menos essa foi a tentativa até o advento das políticas públicas de ações afirmativas, quando então os debates se acirraram e a população negra, até então esquecida pela grande mídia passa a ocupar as principais páginas de jornais.

Durante mais de um século, a despeito das lutas dos movimentos negros, a mídia praticou o que Pierre Nora (1993) chama de "excesso de memória" e "excesso de esquecimento". Ou seja, na prática midiática, a ampla visibilidade é para a população branca (suas histórias de vida, de sucesso, de fracasso, cotidiano, enredos e ficções). Em contrapartida, ao dar tal visibilidade, essa mesma mídia pratica o "abuso de esquecimento", o que significa ignorar a

\footnotetext{
${ }^{14} \mathrm{Cf}$. entrevista concedida a autora.
} 


\section{Observatório}

ISSN n² 2447-4266

Vol. 4, n. 3, maio. 2018

DOI: https://doi.org/10.20873/uft.2447-4266.2018v4n3p783

existencia da população negra. A invisibilidade acontece em todas as esferas, seja existencial, profissional, amorosa ou social. Trata-se de uma cultura de esquecimento, a fim de considerar apenas os sujeitos brancos, exatamente igual o que se praticava no século XIX e inicio do XX, na tal construção do projeto de nação, no qual a população negra não existía. O desejo do país era do embranquecimento.

Ao afrodescendente é negado a responsabilidade do Estado com relação ao seu destino, bem-estar social ou inserção nas esferas públicas de decisão e de poder. De tempos em tempos é comum a mídia quebrar a invisibilidade do afro-brasileiro, ao publicar matérias em que uma determinada pessoa aparece como bem sucedida. O discurso é de esforço pessoal, de superação, de força e de boa vontade. Ora, essa narrativa descontextualiza totalmente o sujeito e coloca no plano pessoal o sucesso ou fracasso da sua própria vida. Desse modo, aqueles que não têm oportunidade e sofrem as chagas do racismo, que veem as portas se fecharem sobre si a cada dia aparecem como preguiçosos, sem força de vontade, ou algo do tipo, repetindo a mesma prática do pós-abolição: Cada um por si.

A conclusão a que se chega é que a mídia ao praticar a invisibilidade do afro-brasileiro está reforçando uma ideología construída pelo Estado e hoje ainda presente nas instituições. Revela o compromisso das grandes empresas de comunicação não com o ethos social, nem com a ética, nem com a democracia, mas com o poder instituído. Reforça a teoría de Sodré do bios virtual ou midiático, qual seja, um novo modo de existencia dos sujeitos atravessados pela midiatização de carater techno-mercadológico. Uma vida regida pelas regras do mercado, pelas regras do consumo, tendo como pano de 


\section{Observatório}

DOI: https://doi.org/10.20873/uft.2447-4266.2018v4n3p783

fundo de sustentação e legitimidade a visibilidade do espetáculo midiático, como já diziam Gui Debord, Baudrillard, Sodré, dentre outros.

Nessa cultura do consumo, as lutas políticas se tornam secundárias e dependendo do interesse, invisíveis, como é o nosso caso em análise. Contudo, há de se ressaltar uma mudança recente na esfera pública política que tem potencial transformador. São as ações afirmativas e as cotas raciais implantadas no início do XXI, e que já mudaram os campi das universidades públicas brasileiras, até recentemente, locus do privilégio branco. Além dos cursos de graduação, os programas de pós-graduação das universidades públicas começam a abrir para os afrodescendentes, em nível de mestrado e doutorado. Isso representa a formação de novos intelectuais negros com forte potencial de mudanças no país para as próximas gerações. Tais medidas ampliam as arenas de disputas e novas mídias contra-hegemônicas podem surgir.

\section{Referências}

ALENCASTRO, Luiz Felipe de. Parecer sobre a Arguição de Descumprimento de Preceito Fundamental, ADPF/186 (2010), apresentada ao Supremo Tribunal Federal. 2012.

ALVES, U. F. José do Patrocínio: a imorredoura cor do bronze. Rio de Janeiro: Ed. Garamond, 2009.

CARVALHO, José Murilo de. A construção da ordem: teatro das sombras. Rio de Janeiro: Ed. Civilização Brasileira, 2006.

Os Bestializados: o Rio de Janeiro e a República que não foi. São

Paulo: Ed. Companhia das Letras, 2012. 


\section{Observatório}

ISSN n² 2447-4266

Vol. 4, n. 3, maio. 2018

DOI: https://doi.org/10.20873/uft.2447-4266.2018v4n3p783

CHANDLER, Daniel; MUNDAY, Rod. Oxford A Dictionary of Media and Communication. Current Online Version, 2014. Disponível em www.oxford reference.com. Acesso em 14/05/2015.

COSTA, Emilia Viotti da. Da monarquia à república: momentos decisivos. São Paulo: Ed. Unesp, 2007.

CUTI. Quem tem medo da palavra negro. Belo Horizonte, Mazza Ed. 2010.

COUTINHO, Carlos Nelson. Gramsci: Um estudo sobre seu pensamento político. Rio de Janeiro, Ed. Civilização Brasileira, 2007.

COUTINHO, E. Granja. A Comunicação do Oprimido e outros ensaios. Rio de Janeiro, Mórula Editoria, 2014.

DOMÍNGUEZ, María Eugênia. O 'Afro' entre os imigrantes em Buenos Aires: Reflexões sobre as diferenças. Dissertação de Mestrado. PPGAntropologia/UFSC. Florianópolis, 2004.

DURKHEIM, Émile; MAUSS, Marcel. Algumas formas primitivas de classificação - Contribuições para o estudo das representações coletivas (1903). In Ensaios de Sociologia. São Paulo, Ed. Perspectiva, 1981.

FANON, Frantz. Pele negra, máscaras brancas. Ed.EdUFBA, 2008.

FAUSTO, Boris. História do Brasil. São Paulo: Ed. USP, 2007.

FREIRE, José R. Bessa. Universidade, Ações afirmativas e reação de intelectuais: depoimento. [22 de maio, 2015]. Rio de Janeiro. Entrevista concedida a Zilda Martins.

FIGUEIREDO, Fabio Bagueiro. A história da África - Módulo 1. Brasília: Ministério da Educação. Secretária de Educação Continuada, Alfabetização e Diversidade; Salvador: Centro de Estudos Afro Orientais, 2011.

GUÉRIOS, Rosário Ferâni Mansur. Tabus Lingüísticos, aum. $2^{\mathrm{a}}$ ed. São Paulo: Editora Nacional, 1979.

LA MADRID, Maria. Evento Tempos da América Latina Afro-indígena: Segregação, Dissimulação, Integração. Mesa de Debate da I Mostra Afro em 


\section{Observatório}

ISSN n² 2447-4266

Vol. 4, n. 3, maio. 2018

DOI: https://doi.org/10.20873/uft.2447-4266.2018v4n3p783

Foco. Argentina, 2006. Disponível: http://www.ipeafro.org.br/10_afro_em_foco/ TEMPOS_DA_AMERICA_LATINA.pdf. Acesso em 26.06.2011.

LOPES, Nei. Nei Lopes, Negros na cultura brasileira. In: SANTOS, Joel Rufino dos; LOPES, Nei; COSTA, Haroldo. Nação Quilombo. Rio de Janeiro, ND Comunicação, 2010.

LORENZI-CIOLDI, Fabio. Les représentations des groupes dominants et dominés. - Saint-Martin-d'Hères (Isère): PUG, 2002.

NABUCO, Joaquim. Manifesto da Sociedade Brasileira contra a Escravidão. Gazeta de Notícias, Rio de Janeiro, 28/09/1880, p.3. Disponível em: http://hemerotecadigital.bn.br/acervo-digital/gazeta-noticias/103730. Acesso em: 02/04/2013.

NORA, Pierre. Entre Memória e História: a problemática dos lugares. Tradução; Yara Aun Khoury. In: Projeto História: Revista do Programa de Estudos PósGraduados em História e do Departamento de História da PUC-SP, n. 10, Educ Editora da PUC, São Paulo, 1993.

PAIXÃO, Marcelo. A Lenda da Modernidade Encantada: por uma crítica ao pensamento social brasileiro sore relações raciais e projeto de Estado-Nação. Curitiba, Ed. CRV, 2014.

POLLACK, Michael. Memória, esquecimento e silêncio. 1989. Disponível em: http://www.uel.br/cch/cdph/arqtxt/Memoria_esquecimento_silencio.pdf. Acesso em: 23/08/2011.

RICOEUR, Paul. O esquecimento. In A memória, a história e o esquecimento, Campinas: Ed. Unicamp, 2007.

RIBEIRO, Ana Paula Goulart; BRASILIENSE, Danielle Ramos. Memória e narrativa jornalística. In: RIBEIRO, Ana Paula Goulart; FERREIRA, Lucia Maria Alves (Orgs.). Mídia e Memória - A produção de sentidos nos meios de comunicação. Rio de Janeiro, Ed. Mauad X, 2007.

RANCIÈRE, Jacques. Entrevista Jacques Rancière. A associação entre arte e política, segundo o filósofo Jacques Rancière. Por Gabriela Longman e Diogo 


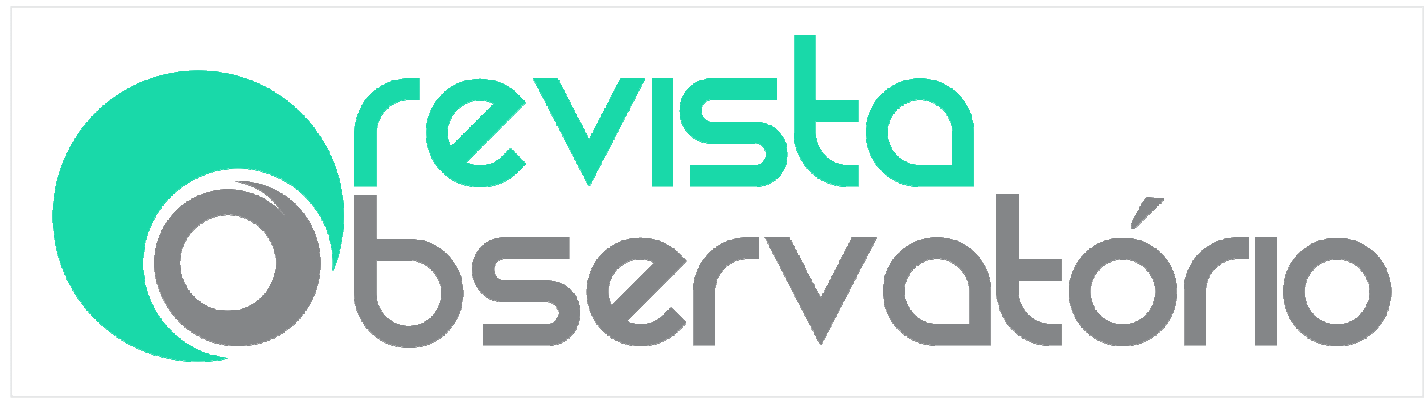

ISSN n² 2447-4266

Vol. 4, n. 3, maio. 2018

DOI: https://doi.org/10.20873/uft.2447-4266.2018v4n3p783

Viana. Revista Cult, edição 139, 2009. Disponível em: http://revistacult .uol. com. br/home/2010/03/ entrevista-jacques-ranciere/. Acesso em 25/07/2014.

SALGADO, Joaquim Carlos. A ideia de justiça em Hegel. São Paulo, Edições Loyola, 1996.

SANTOS, Joel Rufino dos. A Metamorfose do Negro. In: SANTOS, Joel Rufino dos; LOPES, Nei; COSTA, Haroldo. Nação Quilombo. Rio de Janeiro, ND Comunicação, 2010.

SODRÉ, Muniz. A Ciência do Comum: Notas para o método comunicacional. Petrópolis: Ed. Vozes, 2014.

Joaquim Barbosa é um lugar. Observatório da Imprensa. (2014). Disponível em: http://observatoriodaimprensa.com.br/jornal-de-debates/_ed 807_joaquim_barbosa_e_um_lugar/. Acesso em: 25/07/2014.

Reinventando a Educação. Rio de Janeiro. Ed. Vozes, 2012.

A verdade seduzida. Rio de Janeiro, DP\&A Editora, 2005.

Claros e Escuros. Rio de Janeiro, Ed. Vozes, 2000. 